\title{
9
}

\section{Optimization of Foundation of Bridge on Soft Ground}

\author{
Y.Demura* and M.Matsuo** \\ * Department of Civil Engineering, Ishikawa National College of Technology, \\ Japan \\ ** Department of Geotechnical and Environmental Engineering, \\ Nagoya University, Japan
}

\begin{abstract}
Presented is a procedure of optimizing the design of bridge-pier foundations constructed on soft ground which is likely to experience the long-time deformation due to the weight of the bridge. The whole structure of a bridge consisting of the superstructure and the foundations should be designed as a whole in such a way that the total expected cost of the whole structure become minimum. This procedure is totally different from the current design method in which the superstructure and the foundations are treated as a set of separate systems rather than as a total system consisting of subsystems, i.e., the superstructure and the foundations. In evaluating the total expected cost of a bridge, the construction cost both of the superstructure and the foundations as well as the damage occurrence probability should be taken into account.
\end{abstract}

Keywords: Foundation of Bridge, Soft Ground, Optimum Design, System Reliability, Bayes' Theorem

\section{INTRODUCTION}

Figure 1 shows a sketch of a bridge placed on pile-supported piers resting on the bearing stratum overlain by the soft clay layer. The pier will settle by amount of $\mathbf{s}$ due to the consolidation of the ground. The settlement is induced by the penetration of the pile-tip into the bearing stratum. The piles are drawn down by the negative friction caused by the consolidation of the clay layer loaded by the weight of the embankment. The purpose of this study is to propose the methodology of optimizing the foundation of structure on soft ground.

Suppose we have two bridges $\mathrm{A}$ and $\mathrm{B}$, one of which, bridge $\mathrm{A}$ is designed with relatively low safety factor of foundation against the settlement, while the other, bridge $\mathrm{B}$ is designed with relatively high safety factor of foundation. The foundation of bridge 


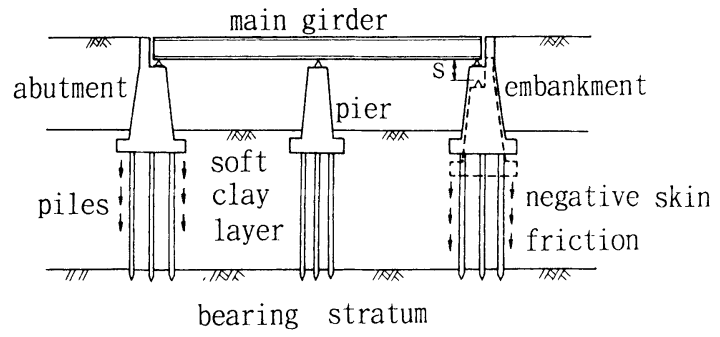

Figure 1 Bridge Constructed on Soft Ground

A is inexpensive, but likely to suffer from the unfavorable settlement with high probability. The settlement of foundation results in the additional stresses in the main girder, i.e., the main girder will have high probability of failure. Hence, the maintenance cost of main girder is expensive. The maintenance cost includes the repair works to be needed due to the future settlement. In the case of the other bridge $B$, the construction cost of foundation is expensive, but the maintenance cost of main girder is inexpensive. The comparison of the bridges $\mathrm{A}$ and $\mathrm{B}$ indicates the existence of the safety factor against the settlement which corresponds to the minimum summation of the construction cost and the maintenance cost. Figure 2 shows the relationship between the safety factor of foundation $G_{\text {sub }}$ and the costs of the main girder and foundation. It should be recognized that the maintenance cost of main girder varies as a function of the safety factor of main girder.

In the procedure described in this paper, (i) we consider the whole structure as a system consisting of two subsystems, i.e., the superstructure (main girder) and substructure (foundation), and (ii) we choose the optimum design so as to realize the minimum of the total expected cost, i.e., the summation of the construction cost and the expected loss of the whole system.

An accurate prediction of the settlement of the piers is unavoidably needed in such a

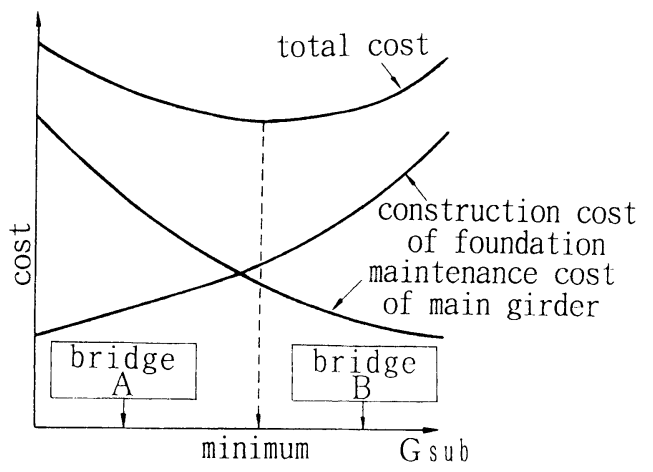

Figure 2 Relationship between Safety Factor and Cost 
procedure. The model proposed in this paper includes the probabilistic settlement prediction method developed by collecting a number of case records of the settlement of bridge piers.

\section{OPTIMIZATION PROCEDURE}

The objective function of the system to be optimized is in principle given as

$E\left[C_{T}\right]=C_{C, \text { sup }}\left(A_{\text {sup }}\right)+C_{C, \text { sub }}\left(A_{\text {su }}\right)+\sum C_{F}\left(D_{K}\right) P\left(D_{K} ; A_{\text {sup }}, A_{\text {sub }}\right)$

in which $\mathrm{E}\left[\mathrm{C}_{\mathrm{T}}\right]$ denotes the total expected cost, $\mathrm{A}_{\text {sub }}$ the design variable of the substructure, $A_{\text {sup }}$ the design variable of superstructure, $C_{c \text {. sub }}$ the construction cost of substructure, $C_{C}$, sup the construction cost of the superstructure, and $D_{K}$ denotes the combination of the damages done to the superstructure and to the substructure. The settlement-caused damages to the superstructure are assumed to be dependent from the settlement-caused damages to the substructure. $D_{K}$ should be evaluated by taking the mechanical and functional interactions between the superstructure and substructure into account. An example will be presented later. $P\left(D_{K}\right)$ is the occurrence probability of $D_{K}$, and $\sum C_{F}\left(D_{K}\right) P\left(D_{K} ; A_{\text {sup }}, A_{\text {sub }}\right)$ is the expected loss produced by $D_{K}$.

The optimum design choice is given by

$\left(A_{\text {sup }}^{*}, A_{s u b}^{*}\right)=\min E\left[C_{T}\left(A_{s u p}, A_{s u b}\right)\right]$

in which $\mathrm{A}_{\mathrm{sup}}^{*}$ and $\mathrm{A}_{\mathrm{sub}}^{*}$ are the optimum design variables of the superstructure and the substructure selected out of many design alternatives, $A_{\text {sup }}$ and $A_{\text {sub }}$.

\section{OCCURRENCE PROBABILITY OF SETTLEMENT}

Suppose a bridge shown in Figure 3 . The differential (uneven) settlement $\delta$ is

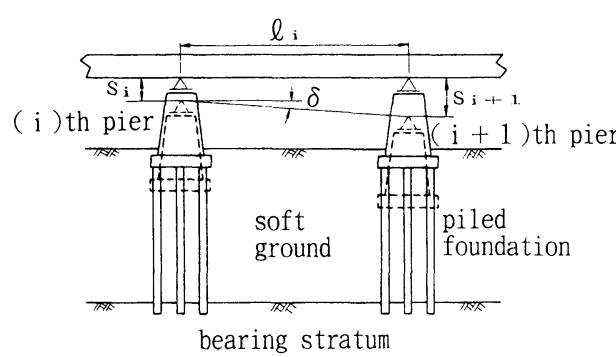

Figure 3 Differential Settlement

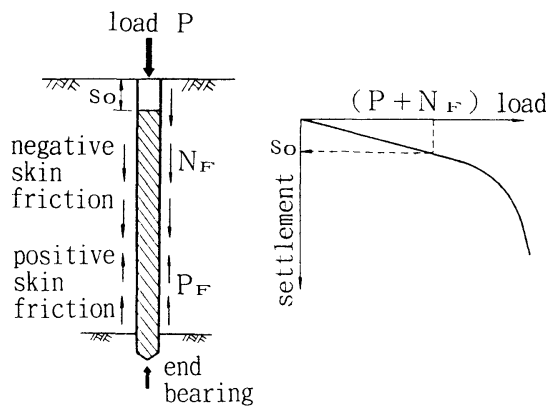

Figure 4 Estimation of Settlement of Pier 
defined by

$\delta=\frac{\mathbf{s}_{\mathrm{i}+1}-\mathbf{s}_{\mathrm{i}}}{1_{\mathrm{i}}}$

in which $S_{i}$ is the settlement of $i$-th pier and $1_{i}$ is the span length between $i$-th and $(i+1)$-th piers.

Let us estimate the occurrence probability of differential settlement of the piers.

(i) Calculate the differential settlement $\delta_{0}$ by

$\delta_{0}=\frac{\mathbf{s}_{0, i+1}-\mathbf{s}_{0, i}}{1_{i}}$

in which the settlement $\mathbf{S}_{0, i}$ is to be estimated from the results of vertical loading test of a pile by means of the conventional method (see Figure 4 ).

(ii) The differential settlement estimated by Eq.(4) is known to be somewhat different from the average of the actually observed differential settlement $\delta$ through a number of past case histories. The comparison of $\delta_{0}$ and $\delta$ leads to a correction factor $\mathrm{H}$, see the example shown later. Then, using thus obtained empirical factor $\mathrm{H}$, calculate the differential settlement $\delta$ which is most likely to take place in the field,

$\delta=\mathrm{H} \cdot \delta_{0}$

(iii) Estimation of $\delta_{0}$ is accompanied by many sources of uncertainty, such as the error in estimating the friction between the piles and the subsoil (needed in estimation of the negative skin friction), the error in estimating the settlement of each pile etc. Then let us assume that $\delta_{0}$ and $\mathrm{H}$ are random variables, and hence, $\delta$ should also be a random variable.

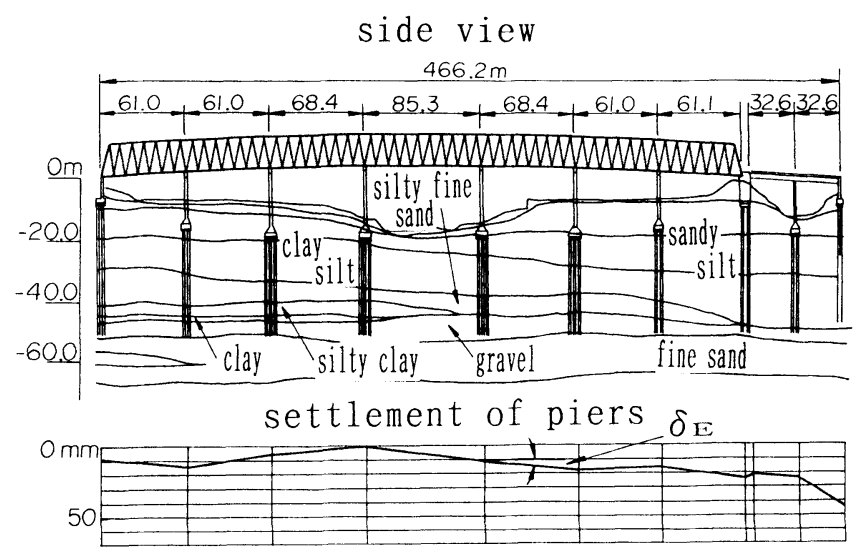

Figure 5 Example of Measured Settlement of Pier 


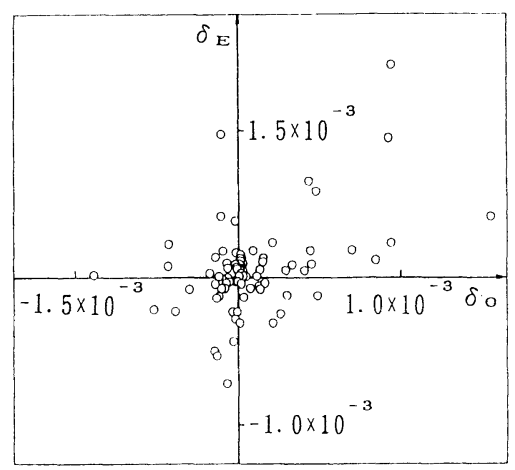

Figure 6 Comparison between Observed Values and Calculated Values

(iv) Calculate the probabilistic distribution of $\delta_{0}$ from the probabilistic distributions of errors arising from the above mentioned sources of error. The probabilistic parameters of the correction factor $\mathrm{H}$ is obtained, as seen later, based on a number of settlement records processed through Bayes' theorem. The settlement records were collected from many bridge piers which suffered from the differential settlement in the past. Considering those observed differential settlements $\delta_{\mathrm{E}}$ as the samples of $\delta$, we get the distribution of parameter $\theta_{\mathrm{H}}$ of the probabilistic distribution of correction factor $\mathrm{H}$ by using the equation (6).

$$
\zeta^{1}\left(\theta_{H}\right)=\frac{\prod_{n S}^{i=1} f_{\delta i}\left(\delta_{i}=\delta_{E i} \mid \theta_{H}\right) \zeta^{0} \theta_{H}}{\int \prod_{n S}^{i=1} f_{\delta i}\left(\delta_{i}=\delta_{E i} \mid \theta_{H}\right) \zeta^{0} \theta_{H} d \theta_{H}}
$$

In Eq.(6), $\zeta^{0}\left(\theta_{\mathrm{H}}\right)$ denotes the prior distribution of $\theta_{\mathrm{H}}$ while $\zeta^{1}\left(\theta_{\mathrm{H}}\right)$ the posterior distribution of $\theta_{\mathrm{H}}$. And $\mathrm{f}_{\delta \mathrm{i}}\left(\delta_{\mathrm{i}}=\delta_{\mathrm{Ei}} \mid \theta_{\mathrm{H}}\right)$ is the conditional distribution of $\delta$ for a given value of $\theta_{\mathrm{H}}$ derived from the probabilistic distribution of $\mathrm{H}$ and $\delta$. " $\mathrm{i}$ " is the
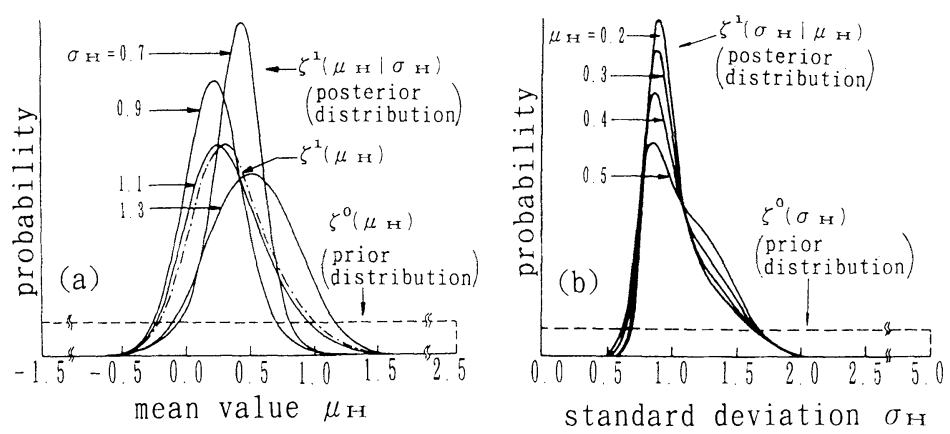

Figure 7 Posterior Distribution of Probabilistic Parameters of Correction Factor 
numerical order of the observed case record. $\mathbf{n}_{\mathrm{s}}$ is the number of observed case records.

Figure 5 shows an example of a bridge which suffered from the differential settlement. $\delta_{\mathrm{E}}$ is the observed differential settlement. In Figure $6, \delta_{\mathrm{E}}$ is plotted against the differential settlement $\delta_{0}$ calculated by the conventional method. Each data point indicates the mean value of random variables $\delta_{0}$ and the sample of $\delta$. There exists a correlation between the observed values and the calculated values. Those results indicate that Eq. (5) is acceptable and the correction factor $\mathrm{H}$ should be random variable.

Figures 7 ( a ), ( b ) show the posterior distributions $\zeta^{1}\left(\theta_{\mathrm{H}}\right)$ obtained by assuming that the prior distributions of the mean value of $\mathrm{H}$ and the standard deviation of $\mathrm{H}$ are uniform. $\mu_{\mathrm{H}}$ is the mean value of $\mathrm{H}$, and $\sigma_{\mathrm{H}}$ is the standard deviation. Those posterior distributions will be used in the estimation of occurrence probability of differential settlement needed in the optimization procedure.

\section{EXAMPLE}

The bridge to be used here as an example is shown in Figure 8 . It is a plate girder bridge constructed on a soft ground. As the design alternative of the super structure, the flange thickness of girder is taken. As the design alternative of the substructure, the area of the thin film covering the pile is used. This film is fixed to the pile surface to reduce the friction between the pile and soil aiming at the reduction of the negative skin friction. The input data for the numerical calculation are listed in tables 1 and 2 .

The damage possibly done to the foundation by the negative skin friction is classified as $D_{\text {sub. } 1}$ and $D_{\text {sub. 2 }} . D_{\text {sub, } 1}$ denotes the situation in which the excessive settlement takes place resulting in the necessity of reconstruction of the foundation. $D_{\text {sub. } 2}$ denotes the complement event of $D_{\text {sub, } 1}$ in which the addition of the stress in the girder flange is more than negligible. $D_{\text {sup, } 1}$ denotes the situation in which the main girder have yielding or buckling in the main girder. $D_{\text {sup. } 2}$ denotes the complement event of $D_{\text {sup. } 1}$.

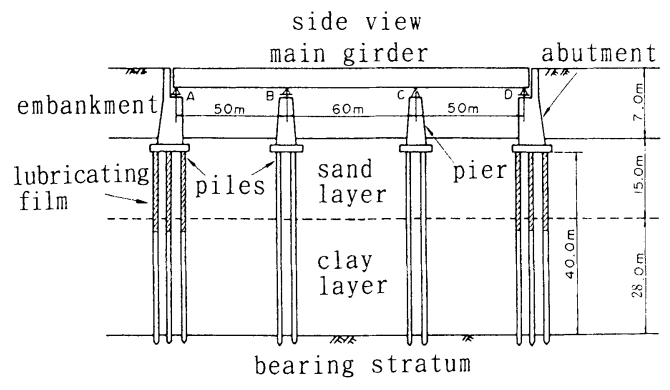

Figure 8 Numerical Example

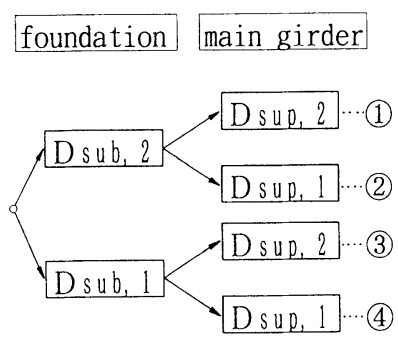

Figure 9 Combination of Damages 
Table 1 Probabilistic Input

\begin{tabular}{|l|l|c|c|}
\hline & & $\begin{array}{l}\text { actual } \\
\text { value }\end{array} / \begin{array}{l}\text { nominal } \\
\text { value }\end{array}$ & $\begin{array}{c}\text { coefficient } \\
\text { of variation }\end{array}$ \\
\hline \multirow{3}{*}{ foundation } & $\begin{array}{l}\text { negative } \\
\text { friction }\end{array}$ & 0.87 & 0.33 \\
\cline { 2 - 4 } & $\begin{array}{l}\text { settlement } \\
\text { of pile }\end{array}$ & 0.38 & 0.087 \\
\hline \multirow{2}{*}{ main girder } & stress & 0.48 & 0.36 \\
\cline { 2 - 5 } & strength & 1.15 & 0.10 \\
\hline
\end{tabular}

Table 2 Cost (yen)

\begin{tabular}{|l|l|l|}
\hline \multirow{2}{*}{ foundation } & construction & $2.8 \times 10^{3} / \mathrm{m}^{3}$ \\
\cline { 2 - 3 } & maintenance & $5.0 \times 10^{7}$ \\
\hline \multirow{2}{*}{ main girder } & construction & $4.0 \times 10^{4} / \mathrm{kN}$ \\
\cline { 2 - 3 } & maintenance & $62.5 \times 10^{9}$ \\
\hline
\end{tabular}

The expected loss is estimated for the cases depending on the combination (see Figure 9 ) of degree of the differential settlement and the degree of damage to the main girder. For example, see the case (1) shown in Figure 9 . In this case, the differential settlement was of class $D_{\text {sup. 2. }}$. The maintenance of the foundation is needed. The expected loss for this case is estimated by Eq.(7).

$\mathrm{E}\left[\mathrm{C}_{\mathrm{F}}\right]_{\Phi}=\mathrm{P}\left(\mathrm{D}_{\text {sub. } 2}\right)\left[\mathrm{C}_{\mathrm{MF}}+\mathrm{C}_{\mathrm{MG}} \mathrm{P}\left(\mathrm{D}_{\text {sup. } 2}\right)\right]$

$\mathrm{E}\left[\mathrm{C}_{\mathrm{F}}\right]_{\Phi}$ denotes the expected loss for the case (1). $\mathrm{C}_{\mathrm{MF}}$ and $\mathrm{C}_{\mathrm{MG}}$ are the costs for the repair of foundation and main girder. $P\left(D_{\text {sub. } 2}\right)$ denotes the occurrence probability of the differential settlement $D_{\text {sub. 2. }} P\left(D_{\text {sup. 2 }}\right)$ denotes the probability of failure of the main girder. In the case (3), the differential settlement was of class $D_{\text {sub. } 1}$ resulting in the

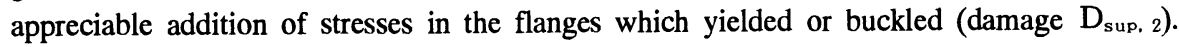
The expected loss for this case is estimated by

$$
\mathrm{E}\left[\mathrm{C}_{\mathrm{F}}\right]_{\circledast}=\mathrm{P}\left(\mathrm{D}_{\text {sub, } 1}\right)\left[\mathrm{C}_{\mathrm{MG}} \mathrm{P}\left(\mathrm{D}_{\text {sup. } 1} \mid \mathrm{D}_{\text {sub. 1 }}\right)\right]
$$

in which $\mathrm{E}\left[\mathrm{C}_{\mathrm{F}}\right]_{3}$ denotes the expected loss for the case (3), $\mathrm{P}\left(\mathrm{D}_{\text {sub, 1 }}\right)$ denotes the occurrence probability of the differential settlement $D_{\text {sub. 1, }} P\left(D_{\text {sup. } 2} \mid D_{\text {sub. 1 }}\right)$ denotes
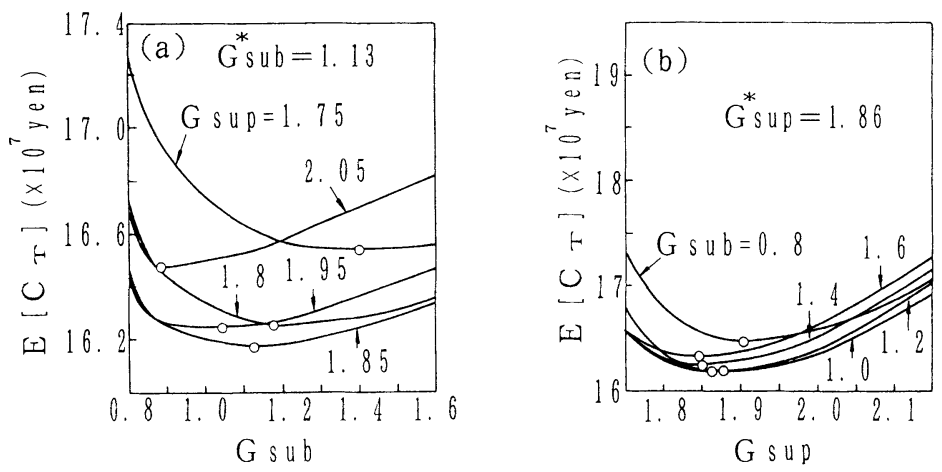

Figure 10 Optimum Solutions 
the probability of failure of the main girder subjected to the additional stresses. Each case shown in Fig. 9 is handled in the same fashion. The summation of the expected losses for all the cases plus construction cost is the objective function which we try to minimize by properly choosing the design alternatives, $A_{\text {sup }}$ and $A_{\text {sub }}$.

Figure 10 show the final results of the above mentioned optimization procedure. The abscissa of Figure 10 (a) is the safety factor $G_{\text {sub against the differential }}$ settlement of the foundation, while the ordinate is the total expected cost $E\left[C_{T}\right]$ plotted against $G_{\text {sub }}$ with the safety factor $G_{\text {sup }}$ of the main girder as a parameter. The abscissa of Figure $10(\mathrm{~b})$ is the safety factor $G_{\text {sup }}$ of the main girder and the parameter is the safety factor of foundation. The safety factors at which the total expected cost becomes minimized are $G_{\text {sup }}=1.86$ and $G_{s u b}=1.13$. These two values are the optimum combination of two safety factors for the super and sub structure. It may be interesting to compare to these two values with the safety factors required by the current conventional design codes, i.e., $G_{\text {sup }}=1.7$ and $G_{\text {sub }}=1.4$. The safety factor of foundation in the optimum design is smaller than the safety factor in the current design code. The safety factor of main girder in the optimum design is larger than the safety factor in the current design code. These results are due to the settlement of foundation at the optimum design which is larger than the settlement allowable in the current design code .

\section{CONCLUSIONS}

The optimization procedure for the bridge design is briefly outlined and an example of the application of the optimization procedure is presented. As the conclusions, followings should be noted.

(1) The use of the objective function derived for the total system including both the superstructure and the substructure leads to the optimum design more rational than the design optimized separately for the superstructure and substructure.

(2) The example presented in this paper resulted the safety factors for the superstructure and substructure which happened to be fairly close to the safety factors required by the conventional design codes.

(3) The proposed method seems to be useful in seeking the bridge designs with much harmony in the whole system of the superstructure and substructure.

\section{REFERENCES}

1. M.Matsuo and Y.Demura, Proc. of Japan Society of Civil Engrg. Vol.340/ III -4, pp.129-138, 1984.12 (in Japanese).

2. M.Matsuo and Y.Demura, Proc. of Japan Society of Civil Engrg. Vol.364/ III -4, pp.215-224, 1985.12 (in Japanese). 